\title{
SUS: em construção ou desconstrução?
}

\section{SUS: in construction or dismantling?}

\section{SUS: en construcción o en desmantelamiento?}

\begin{abstract}
Ana Luiza Braz Pavão | ana.pavao@icict.fiocruz.br Fundação Oswaldo Cruz (Fiocruz), Instituto de Comunicação e Informação Científica e Tecnológica em Saúde (ICICT), Laboratório de Informações em Saúde (LIS). Rio de Janeiro, RJ, Brasil.
\end{abstract}

Palavras-chave: Sistema Único de Saúde; SUS; seguridade social; reforma sanitária; Estado; cidadania; saúde; Constituição.

Keywords: Unified Health System; SUS; social security; Brazilian Sanitary Reform; state; citizenship; health; Constitution.

Palabras clave: Sistema Unico de Salud; SUS; Reforma Sanitaria brasileña; Estado; ciudadanía; salud; Constitución.

O Sistema Único de Saúde, ou SUS, como é conhecido, é o sistema de saúde vigente no Brasil desde a promulgação da Constituição Federal de 1988. Diversos são os seus princípios e diretrizes, mas o primeiro deles, aquele que o caracteriza como modelo de atenção à saúde baseado na seguridade social, é o princípio da universalidade do acesso, ou seja, a sua cobertura universal. Este princípio ou diretriz ético-doutrinária garante que todos os cidadãos tenham acesso aos serviços de saúde brasileiros de forma livre e gratuita, baseando-se na premissa de que a "saúde é um direito de todos e um dever do Estado"1.

A criação do SUS foi um marco importante para a saúde pública brasileira, visto que, durante várias décadas anteriores ao seu surgimento, a assistência à saúde era ligada à Previdência Social e se restringia apenas aos trabalhadores formais, ou seja, àqueles que contribuíam para a Previdência e tinham carteira assinada. O restante da população não tinha cobertura de assistência garantida pelo Estado.

Durante os anos anteriores ao surgimento do SUS, sobretudo no período do Regime Militar, o movimento da Reforma Sanitária teve papel fundamental na implantação do novo modelo de atenção. Esse movimento teve bases universitárias e envolveu profissionais de saúde, acadêmicos, especialistas e pessoas vinculadas à saúde. Buscava transformar o setor de saúde no Brasil em prol da melhoria das condições de saúde da população ao alcance do direito da cidadania. Tinha como diretrizes a universalização, a acessibilidade, a descentralização, a integralidade e a participação comunitária. As suas propostas foram consolidadas 
no relatório final da $8^{\text {a }}$ Conferência Nacional de Saúde, de 1986, que aprovou a unificação do sistema de saúde, o conceito ampliado de saúde, o direito à cidadania e o dever do Estado. Esse relatório serviu de base para as discussões na Assembleia Constituinte de 1987, que culminou com a aprovação do texto referente à saúde na Constituição de 1988.

A integralidade é considerada, por diversos autores, um dos princípios mais representativos do SUS e que traduz a ideia de um "conjunto articulado e contínuo das ações e serviços preventivos e curativos, individuais e coletivos, exigidos para cada caso, em todos os níveis de complexidade do sistema”". Segundo esse princípio, a garantia de uma assistência à saúde integral é direito de todo e qualquer cidadão e deve ser prioridade do Estado. Outro princípio fundamental é o da equidade, que tem como objetivo reduzir as desigualdades, através da assistência dada de acordo com as necessidades de cada um. E, entre os seus princípios organizacionais/operativos, destaca-se a participação social, expressa pela participação dos usuários nos Conselhos e Conferências de Saúde e garantida pela Lei 8.142, de 1990³.

A importância de se revisitar o histórico do SUS se dá pela necessidade de resgate dos valores que inspiraram o movimento da Reforma Sanitária. Saúde como direito do cidadão, direito da população e dever do Estado, garantido por Lei. Atualmente, cerca de 75\% da população brasileira depende do SUS para ter acesso aos serviços de saúde, pois ainda é a minoria que tem acesso aos planos privados. Isso representa aproximadamente 150 milhões de habitantes, considerando uma população de 200 milhões. Vale lembrar que, no contexto de expansão do setor privado em que o SUS foi criado, a Constituição teve que prever a coexistência de um sistema suplementar de saúde, o dos planos e seguros de saúde.

Isabela Soares Santos, na seção Notas de conjuntura, traz uma ampla reflexão sobre a situação atual do SUS e suas relações com o setor privado, e mostra que a mistura entre o público e o privado existe em todos os sistemas de saúde do mundo, mas que há de se ter atenção se é o interesse público ou o privado que predomina. A autora também questiona a relação público-privada, nesse caso, em que o setor privado é financiado por investimentos públicos, em detrimento de investimentos no SUS. Da mesma forma, ressalta os avanços alcançados pelo sistema público de saúde, apesar dos grandes embates enfrentados desde a sua criação.

O maior desafio nos tempos atuais é a manutenção dos princípios do SUS e o aperfeiçoamento desse sistema, que envolve um conjunto de equipamentos, estabelecimentos de saúde, profissionais de saúde, usuários e não-usuários, insumos, informações, verbas e instâncias de participação. O SUS não deve ser desconstruído, pois isso representaria a desintegração das partes que o compõem e a fragmentação de iniciativas. Ao contrário, a sua construção permanente permite o diálogo contínuo entre a sociedade civil e o governo, o diálogo sobre os recursos destinados à saúde e a ampliação dos direitos. A fim de que o SUS seja aperfeiçoado, alguns desafios devem ser enfrentados, como o subfinanciamento do sistema, a necessidade de modernização da administração pública, a regulação das relações entre público e privado, o desafio da regionalização, entre outros 5 . Por outro lado, nas últimas décadas, houve importantes avanços na saúde pública, como a ampliação da cobertura da Atenção Básica, através da Estratégia de Saúde da Família, que representou a mudança de um enfoque curativo para um preventivo na assistência ${ }^{6}$.

Outro desafio importante no âmbito da saúde pública brasileira atualmente é a emergência da infecção pelo vírus Zika e a sua associação com casos crescentes de microcefalia. $\mathrm{O}$ artigo de Michele Nacif Antunes e colaboradores traz uma análise das principais imagens do aplicativo Instagram compartilhadas por internautas a respeito da epidemia causada por esse vírus. A seção de resenhas traz o texto elaborado por Mônica Mourão Lara Netto sobre o documentário "Zika", de 2016, que apresenta uma reflexão sobre os determinantes sociais da epidemia, ao retratá-la sob a ótica de populações vulneráveis.

Ainda sobre os desafios e conquistas do SUS, o artigo de Lívia Teixeira Tavares e colaboradores traz um estudo de série temporal sobre as taxas de mortalidade geral e por causas evitáveis, em menores de um ano de idade, na Bahia, no período de 2000 a 2012. Os autores mostraram que, apesar da persistência de valores considerados altos de óbitos evitáveis, houve diminuição da taxa de mortalidade infantil geral 
e daquela provocada por causas evitáveis naquele estado. A nota de conjuntura de Isabela Soares Santos cita a melhora alcançada, nos últimos anos, de alguns indicadores para o país como um todo, como as taxas de mortalidade infantil, as taxas de desnutrição em crianças e as taxas de ocorrência de doenças infecciosas, parasitárias e imunopreviníveis. O artigo de Daiane Ellwanger Araujo e colaboradores, por sua vez, traz uma importante contribuição para a avaliação do desempenho das redes de atenção à saúde através da proposição de indicadores que possam auxiliar os gestores na tomada de decisão no âmbito das regiões de saúde.

Após quase 30 anos de sua criação, o SUS se mantém como modelo de atenção à saúde brasileiro, citado internacionalmente como exemplo de política pública inclusiva. Isto se deve às sólidas bases nas quais foi implantado.

\section{Referências}

1. Brasil. Constituição (1988). Constituição da República Federativa do Brasil. Brasília, DF: Senado Federal; 1988.

2. Brasil. Lei no 8.080, de 28 de dezembro de 1990. Dispõe sobre a participação da comunidade na gestão do Sistema Único de Saúde (SUS) e sobre as transferências intergovernamentais de recursos financeiros na área da saúde e dá outras providências. Diário Oficial da União 1990; set 20.

3. Brasil. Lei no 8.142, de 19 de setembro de 1990. Dispõe sobre as condições para a promoção, proteção e recuperação da saúde, a organização e o funcionamento dos serviços correspondentes e dá outras providências. Diário Oficial da União 1990; dez 31.

4. Lima NT, Gerschman S, Edler FC, Suárez JM. Saúde e democracia. História e perspectivas do SUS. Rio de Janeiro: Editora Fiocruz; 2005.

5. Santos L. Sistema Único de Saúde. Os desafios da gestão interfederativa. Campinas: Saberes Editora; 2013.

6. Paim J. Na saúde, tivemos vários momentos muito difíceis, mas conseguimos dar a volta por cima [entrevista a Pavão AL, Bezerra A, Barcellos C, Azevedo FT, Sacramento IP, Carvalho LS, Bochner R, Murtinho R]. Reciis - Rev Eletron Comum Inf Inov Saúde 2016 abr.-jun.; 10(2). [citado 20 set. 2016] Disponível em: http://www.reciis.icict.fiocruz.br/index.php/reciis/article/view/1144/pdf 1144. 